Background: Pulmonary involvement is one of the frequent extra-articular manifestations of rheumatoid arthritis (RA) (1). Biological disease-modifying anti-rheumatic drugs (bDMARDs) are effectively used in the treatment of musculoskeletal findings of RA but their effect on RA-associated lung disease is unclear.

Objectives: The aim of this retrospective study is to evaluate and compare different bDMARD treatments used in RA patients with RA-associated lung disease.

Methods: All RA patients who received bDMARDs between 2008 and 2018 in a single rheumatology centre and had thorax high-resolution computed tomography $(\mathrm{HRCT})$ were reviewed for the findings of lung involvement. Patients with positive finding were included in the study. Following the biologic treatment, whether there was a progression/regression in lung involvement was evaluated by comparing the baseline and the latest thorax HRCT findings. Clinical and laboratory data were collected from medical records.

Results: A total of 40 patients (mean age:62.4 years; $72.5 \%$ women) were included in the study. Clinical and demographic characteristics of patients are summarized in Table 1. During the mean $107.43 \pm 65$ months follow-up period, HRCT findings remained stable in 31 patients $(76 \%)$ and improved in one $(2.5 \%)$, while 7 patients $(17.5 \%)$ had progress in their lung involvement. When patients with and without progress were compared, lung involvement at the diagnosis of RA and the presence of respiratory symptoms at bDMARDs initation was found to be more frequent in the first group $(p=0.023$ and $p=0.020$, respectively). Mean ESH values at bDMARDs initation were also higher in patients who had progress $(p=0.006)$. There was no significant difference between the groups in the age, sex, type of bDMARDs used or other baseline laboratory data. Logistic regression analysis showed that lung involvement at the diagnosis of RA was a significiant independent risk factor for the progress (OR: $11.0,95 \% \mathrm{Cl}=1.48-81.60$ ). There was no statistically difference on progression of HRCT findings between patients received TNFi $(n=22)$ and nonTNFi biologics $(n=18),(p=1.00)$. The mean drug survival of first bDMARD also was not statistically different between groups $(40.83 \pm 21.6$ months in non-TNFi group and $42.23 \pm 40.50$ months in TNFi group $(p=0.90)) .5 / 18(\% 27.8)$ patients in the non-TNFi group and $1 / 22(\% 4.5)$ in TNFi group had died during the follow-up $(p=0.14)$

Table 1. Demographic and clinic characteristics of the patients at the Initiation of BDMARDs.

\begin{tabular}{lc}
\hline Characteristics & $\mathrm{N}=40$ \\
Male/Female, $n$ & $11 / 29$ \\
Age at bDMARDs initiation, years (mean \pm SD) & $56,51 \pm 10.53$ \\
Age at the diagnosis, years (mean \pm SD) & $49,38 \pm 11,7$ \\
Disease duration at bDMARDs initiation, years (mean \pm SD) & $7,15 \pm 5,53$ \\
Past or current smoker, $n(\%)$ & $21 / 40(52.5)$ \\
RF positivity, $n(\%)$ & $29 / 40(72.5)$ \\
ACPA positivity, $n(\%)$ & $35 / 39(89.7)$ \\
Anti-SSA positivity $n(\%)$ & $3 / 9(33.3)$ \\
Patients with Sjögren's syndrome, $n(\%)$ & $5 / 10(50)$ \\
ESR at bDMARDs initiation, (mm/h) & $38,37 \pm 22,2$ \\
CRP at bDMARDs initiation, (mg/l) & $16,08 \pm 14,54$ \\
DAS28 at bDMARDs initiation & $3,68 \pm 1,1$ \\
Respiratory symptom at bDMARDs initation, $\mathrm{n}(\%)$ & $12 / 40(30)$ \\
Lung involvement at the diagnosis, $\mathrm{n}(\%)$ & $8 / 25(24,2)$ \\
Concomitant steroid, $n(\%)$ & $37 / 40(92.5)$ \\
Concomitant MTX, $\mathrm{n}(\%)$ & $16 / 40(40)$ \\
Concomitant other csDMARDs, $n(\%)$ & $31 / 40(\% 77,5)$ \\
Initiated bDMARDs, TNFi/nonTNFi, $n$ & $22 / 18$ \\
RA-lung involvement type based on HRCT findings, $\mathrm{n}(\%)$ & \\
-Rheumatoid nodulosis & $17(42.5)$ \\
-ILD-ground-glass opacity & $12(30)$ \\
-ILD-honeycombing & $11(27.5)$ \\
\hline
\end{tabular}

Conclusion: This study showed that the impact of TNFi and non-TNFi biologic treatments on the course of RA-assosiated lung involvement is similar. It also suggested that lung involvement at the diagnosis of RA was a significiant risk factor for the progress of the pulmonary disease.

References:

[1] Turesson C, O'Fallon WM, Crowson CS, Gabriel SE, Matteson EL. Extraarticular disease manifestations in rheumatoid arthritis: incidence trends and risk factors over 46 years. Ann Rheum Dis. 2003;62(8):722-7

Disclosure of Interests: None declared

DOI: 10.1136/annrheumdis-2020-eular.3440

\section{FRI0100 \\ COMPARISON OF PATIENTS (PTS) WITH RHEUMATOID ARTHRITIS (RA) AMONG DISEASE ACTIVITY CATEGORIES AFTER 6 MONTHS OF TREATMENT WITH A TUMOUR NECROSIS FACTOR INHIBITOR (TNFI): RESULTS FROM THE CORRONA® RA REGISTRY}

J. M. Kremer ${ }^{1,2}$, A. Winkler ${ }^{3}$, L. Anatale-Tardiff', R. Mclean ${ }^{2}$, Y. Shan ${ }^{2}$, P. Moore ${ }^{2}$, N. Tundia ${ }^{4}$, J. Suboticki ${ }^{4}$, J. Tesser ${ }^{5}{ }^{1}$ Albany Medical College, Center for Rheumatology, Albany, New York, United States of America; ${ }^{2}$ Corrona, LLC, Waltham, MA, United States of America; ${ }^{3}$ Missouri State University, Missouri, United States of America; ${ }^{4}$ AbbVie Inc., North Chicago, IL, United States of America; ${ }^{5}$ Arizona Arthritis and Rheumatology Associates, Glendale, AZ, United States of America

Background: Targeting remission (REM) or low disease activity (LDA) is a widely accepted treatment strategy for RA. However, there are limited data on the proportion of pts who achieve these targets, or remain in moderate (MDA) or high disease activity (HDA) following advanced therapy.

Objectives: To estimate the proportion of RA pts in disease activity states (REM, LDA, MDA, and HDA) who were biologic-naïve at initiation and had continuous treatment with a TNFi for 6-12 months in the Corrona RA registry.

Methods: Eligible pts were aged $\geq 18$ years, biologic-naïve, initiated TNFi treatment between January 1, 2010 and July 31, 2019, and had continuous use of a TNFi for 6-12 months. Disease activity was defined based on Clinical Disease Activity Index (CDAl) at the visit closest to 6-month follow-up: REM, $\leq 2.8$; LDA, $>2.8-10 ;$ MDA, >10-22; and HDA, >22. Disease characteristics, disease activity measures, and pt-reported outcomes (PROs) were reported at TNFi initiation and at the 6-month follow-up visit.

Results: 2586 biologic-naïve pts who initiated a TNFi and had continuous use for 6-12 months were included. At TNFi initiation, $167(6 \%)$ were in REM, $479(19 \%)$ had LDA, $907(35 \%)$ had MDA, and $1033(40 \%)$ had HDA. After 6-12 months of treatment, $563(21.8 \%)$ were in REM, $923(35.7 \%)$ had LDA, $674(26.1 \%)$ had MDA, and $426(16.5 \%)$ had HDA. Pts with HDA/MDA at 6-12 months were more likely to have a history of hypertension (32.7\% HDA; $34.0 \% \mathrm{MDA}$; vs $23.6 \% \mathrm{REM}$ ) and had higher mean body mass index (BMI) (30.9 HDA; $31.1 \mathrm{MDA}$; vs $29.0 \mathrm{REM}$ ) at baseline compared with pts in REM. Disease activity measures and PROs were worse in pts with MDA and HDA vs LDA and REM after 6-12 months (Table). Pt Global Assessment was higher than Physician Global Assessment across all groups.

Conclusion: While $57.4 \%$ of pts who initiated a TNFi experienced a favorable outcome, $>40 \%$ required additional or alternative intervention to achieve REM/ LDA. Pts who remained in MDA/HDA continued to have an inadequate response to TNFi (as measured by disease activity measures and PROs) after 6-12 months of treatment compared with those who achieved REM/LDA.

Table. Summary of disease activity measures and PROs in previously biologic-naïve pts at the 6-12-month follow-up visit, stratified by disease activity category at the 6-12-month follow-up visit

\begin{tabular}{lcccc}
\hline \multirow{2}{*}{$\begin{array}{l}\text { Characteristics at 6-12 months, } \\
\text { mean (standard deviation) }\end{array}$} & \multicolumn{5}{c}{ Disease activity category at 6-12 months } \\
\cline { 2 - 5 } & REM ( $n=563)$ & LDA $(n=923)$ & MDA ( $n=674)$ & HDA $(n=426)$ \\
\hline CDAI & $1.2(0.8)$ & $6.2(2.1)$ & $15.4(3.4)$ & $32.7(9.2)$ \\
Tender joint count (28) & $0.1(0.3)$ & $1.0(1.3)$ & $4.3(3.3)$ & $13.4(7.0)$ \\
Swollen joint count (28) & $0.1(0.3)$ & $1.1(1.6)$ & $4.0(3.6)$ & $9.1(5.9)$ \\
C-reactive protein & $6.4(22.7)$ & $7.0(10.6)$ & $11.1(19.9)$ & $12.6(22.1)$ \\
Modified health assessment & $0.1(0.2)$ & $0.3(0.4)$ & $0.5(0.5)$ & $0.8(0.5)$ \\
questionnaire & & & & \\
Pt global assessment & $6.6(6.8)$ & $28.6(20.9)$ & $43.7(25.7)$ & $58.0(22.7)$ \\
Physician global assessment & $3.6(4.3)$ & $12.1(10.4)$ & $27.4(15.9)$ & $44.9(19.8)$ \\
Pt pain assessment & $8.7(11.0)$ & $30.3(23.5)$ & $46.1(27.0)$ & $59.9(24.4)$ \\
Pt fatigue assessment & $15.7(19.2)$ & $34.5(26.6)$ & $48.3(28.0)$ & $59.4(27.5)$ \\
Morning stiffness (min) & $16.5(36.5)$ & $55.4(146.3)$ & $96.9(197.5)$ & $143.6(260.0)$ \\
& & & &
\end{tabular}

Disclosure of Interests: Joel M Kremer Shareholder of: May own stocks and opinions, Grant/research support from: Research and consulting fees from AbbVie Inc., Consultant of: AbbVie, Amgen, BMS, Genentech, Inc., Gilead, GSK, Lilly, Pfizer, Regeneron and Sanofi, Employee of: Corrona, LLC employee, Anne Winkler Consultant of: AbbVie, Pfizer, and Novratis, Speakers bureau: AbbVie, Janssen, Sanofi, Genentech, Celgene, Eli Lilly, and Novartis., Laura Anatale-Tardiff Employee of: Corrona, LLC employee, Robert McLean Employee of: Corrona, LLC, Ying Shan Employee of: Corrona, LLC employee, Page Moore Employee of: Corrona, LLC employee, Namita Tundia Shareholder of: May own stocks and options, Employee of: AbbVie employee, Jessica Suboticki Shareholder of: AbbVie Inc., Employee of: AbbVie Inc., John Tesser Consultant of: Sanofi/Regeneron, Speakers bureau: Sanofi/Regeneron

DOI: 10.1136/annrheumdis-2020-eular.1698 